\title{
Oncologic safety of breast-conserving surgery in breast cancer patients under the age of 35
}

\author{
Incheon Kang1', Joo Heung Kim¹, Seho Park1, Ho Hur2, Hyung Seok Park1, Seung II Kim¹, Young Up Cho ${ }^{1}$ \\ 1Department of Surgery, Yonsei University College of Medicine, Seoul; \\ 2Department of Surgery, National Health Insurance Service Ilsan Hospital, Goyang, Korea
}

Purpose: Breast-conserving surgery (BCS) shows no difference in survival rates compared with total mastectomy. So, BCS is considered standard breast surgery with modified radical mastectomy. But in patients who received BCS, there is a risk of local recurrence in their long term follow up periods. Especially, BCS of young age is controversial regarding oncologic safety because of local recurrence. In this study, we struggle to confirm the oncologic safety of BCS compared with total mastectomy under the age of 35 in South Korea.

Methods: All patients who underwent surgery for breast cancer were 5,366 at Severance Hospital, Yonsei University Health System, from January 1981 to April 2008. Of them, patients younger than 35 years old were 547. We excluded patients who received chemotherapy before surgery and included only stage 1 and 2 patients who identified through the pathology after surgery. Finally, we got 367 patients; total mastectomy was performed in 245 and BCS, in 122. We compared clinicopathological characteristics and oncologic outcomes between two groups using SPSS program.

Results: In patients received BCS, a local recurrence rate was $7.7 \%$ at 5 years and up to $20.3 \%$ at 10 years. In patients received total mastectomy, a local recurrence rate was $1.9 \%$ over 10 years $(\mathrm{P}<0.001)$. However, there was no difference in 5 -year and 10 -year overall survival rates between two groups $(P=0.689)$. Adjuvant chemotherapy decreased local recurrence rate in $B C S$ patients $(P=0.019)$.

Conclusion: So, we concluded that BCS under the age of 35 has oncologic safety with undergoing chemotherapy.

Keywords: Age factors, Breast-conserving surgery, Breast neoplasms, Local neoplasm recurrence, Survival rate

\section{INTRODUCTION}

Breast conserving surgery has been shown by numerous prospective studies to have the same survival rate as total mastectomy, and has currently taken a position alongside modified radical mastectomy as the standard surgical procedure for breast cancer [1-4]. With the increased rate of the early diagnosis of breast cancer through health checkups, breast conserving surgery has steadily become more common. However, while the chance of local recurrence gradually disappears with total mastectomy, patients who undergo breast conserving surgery are known to be in constant

Received: Oct 4, 2016 Accepted: May 25, 2017

Correspondence to: Ho Hur

Department of Surgery, National Health Insurance Service Ilsan Hospital, 100 lisan-ro, lisandong-gu, Goyang 10444, Korea

Tel: +82-31-900-0209, Fax: +82-31-900-0138

E-mail: hoya0430@gmail.com

Copyright $@$ Korean Society of Surgical Oncology

This is an Open Access article distributed under the terms of the Creative Commons Attribution Non-Commercial License (http://creativecommons.org/licenses/by-nc/4.0) which permits unrestricted non-commercial use, distribution, and reproduction in any medium, provided the original work is properly cited. danger of local recurrence, even over the course of long-term follow-up [1]. It is not yet known whether such local recurrence is a manifestation of systemic metastasis or is simply due to the aggressive behavior of the tumor. However, some research supports the proposal that local recurrence is associated with an increased likelihood of systemic metastasis, and according to research conducted by the Early Breast Cancer Trialists' Collaborative Group (EBCTCG), reducing four local recurrences during the first five years can reduce one deathe due to breast cancer after 15 years [58]. Hence, understanding the risk factors of local recurrence and reducing the likelihood of local recurrence is of the utmost importance.

Positive margins are a major risk factor for local recurrence after breast conserving surgery. Typically, total mastectomy is conducted when negative margins cannot be achieved after numerous resections $[9,10]$. In addition, young age has also been reported to be a major risk factor for local recurrence after breast-conserving surgery (BCS) $[8,11,12]$. Hence, many questions have been raised regarding the safety of breast conserving surgery in young breast cancer patients, and the National Comprehensive Cancer Network 
guidelines state that young patients should not undergo BCS. However, some recent prospective research has reported that the survival rate did not differ between young patients who received total mastectomy and those who underwent BCS, suggesting that breast conserving surgery should not be avoided due to age alone $[13,14]$.

Meanwhile, the standards for classifying patients as young have varied across studies, with some considering patients under 50 to be young, and others considering those under 35 to be young. A recent study on the appropriate age range to be considered young, conducted among patients registered in the Korean Breast Cancer Registration Program, concluded that 35 and below is the appropriate boundary [15]. This study observed the prognoses of Korean patients age 35 or below who underwent either a total mastectomy or breast conserving surgery to verify the oncological safety of breast conserving surgery in young Asian patients.

\section{METHODS}

\section{Patients and subjects}

From January 1981 to April 2008, a total of 5,366 patients underwent surgery due to invasive breast cancer at the surgery department of the College of Medicine of Yonsei University. Of these patients, 547 patients were aged 35 and below. The research was conducted only on patients with pathologically confirmed stage 1 or 2 breast cancer, and excluded patients who received chemotherapy prior to surgery or had cancer in both breasts. Of the remaining 371 patients, 1 was excluded due to the absence of records regarding the surgical method, and another 3 were excluded because they had not received radiation treatment. This resulted in a final total of 367 patients, 245 of whom had undergone a total mastectomy, while the remaining 122 had undergone breast conserving surgery. Factors such as the age at the time of diagnosis, histologic subtype, size of the tumor, axillary lymph node metastasis, staging, histologic grade, hormone receptor status, surgical method, margin status, whether radiation treatment was performed, whether chemotherapy was administered after surgery, and whether endocrine therapy was administered were recorded.

Simple local recurrence was defined as a recurrence in the chest wall, including the skin, in the area of the operation for total mastectomy, and was defined as recurrence in the skin and/or breast on the side of the operation for BCS. Recurrence in only the regional lymph nodes was excluded. The time until simple local recurrence was calculated as the time between the day of operation to the day of recurrence. Simple local recurrence was limited to recurrence in the breast that was operated upon. Hence, cases where regional or systemic recurrence occurred either first or simultane- ously were excluded. In such cases, observation was ceased on the day that recurrence was discovered in a different area. Local or whole-body recurrence within 6 months of recurrence in the operated breast was treated as simultaneous recurrence. Systemic recurrence was defined as recurrence in an area beyond the operated breast and the regional lymph nodes. The systemic recurrence free survival period extended from the day of the operation to the day on which systemic recurrence was verified, and observations were ceased on the date of death or on the date of the final hospital visit. The total survival period was defined as extending from the date of surgery to the date of death, regardless of the cause. The final progress observation date was fixed at March 31, 2011. This research was conducted under the approval of the Severance Hospital Institutional Review Board (Approval no. 4-2016-1162).

\section{Statistical methods}

The 2 patient groups were compared with the independent $t$-test for continuous variables, and the chi-square test for categorical variables. The survival curve was obtained using the Kaplan-Meier method, and the 2 patient groups were compared using the logrank test. A Cox proportional hazards model was used to verify that the surgical method was an independent prognostic factor. All statistical analyses were conducted using SPSS ver. 13.0 (SPSS Inc., Chicago, IL, USA), and P-values from the 2-sided test less than or equal to 0.05 were considered to indicate statistical significance.

\section{RESULTS}

\section{Clinical characteristics}

Table 1 shows the characteristics of the patients and the tumors, along with the treatment method. The median age for both patient groups was 32.0 years. The T staging was higher in the patients who underwent a total mastectomy $(\mathrm{P}=0.005)$ and, while not statistically significant, this group also showed higher $\mathrm{N}$ staging $(\mathrm{P}=0.086)$. Hence, based on the tumor characteristics, it would be predicted that the patients who underwent a total mastectomy would have a worse prognosis. However, there were no differences in the systemic treatment received by both groups. Of the $122 \mathrm{pa}$ tients who underwent BCS, negative margins were obtained in 115 , while 2 patients had positive margins. There were no records for the remaining 5 patients.

\section{Local recurrence}

In 13 patients, isolated local recurrence took place after BCS; of these patients, recurrence was diagnosed in 3 within 2 years of surgery, in another 2 from 2 to 5 years after surgery, in 3 from 5 to 10 years after surgery, and in 4 after 10 years. The patients continued 
Table 1. Characteristics of patients aged 35 years or younger undergoing breast conserving surgery (BCS) or mastectomy

\begin{tabular}{|c|c|c|c|}
\hline Characteristic & $\begin{array}{c}\text { BCS } \\
(n=122)\end{array}$ & $\begin{array}{c}\text { Mastectomy } \\
(n=245)\end{array}$ & P-value \\
\hline Age (yr) & & & 0.323 \\
\hline$\leq 30$ & 43 (35.2) & $72(30.1)$ & \\
\hline$>30$ & 79 (64.8) & $167(69.9)$ & \\
\hline Tumor size (pT) & & & 0.005 \\
\hline T1 & $67(54.9)$ & 97 (39.6) & \\
\hline $\mathrm{T} 2$ & $55(45.1)$ & $148(60.4)$ & \\
\hline Nodal status (pN) & & & 0.086 \\
\hline 0 & 90 (73.8) & $159(64.9)$ & \\
\hline $1-3$ & $32(26.2)$ & $86(35.1)$ & \\
\hline Grade & & & 0.356 \\
\hline 1,2 & $56(62.9)$ & 95 (68.8) & \\
\hline 3 & 33 (37.1) & 43(31.2) & \\
\hline Unknown & 33 & 107 & \\
\hline Estrogen receptor & & & 0.028 \\
\hline Negative & $57(54.8)$ & $66(41.0)$ & \\
\hline Positive & 47 (45.2) & $95(59.0)$ & \\
\hline Unknown & 18 & 84 & \\
\hline Chemotherapy & & & 0.41 \\
\hline Done & $94(77.0)$ & $193(80.8)$ & \\
\hline Not done & $28(23.0)$ & 46 (19.2) & \\
\hline Unknown & 0 & 6 & \\
\hline Endocrine therapy & & & 0.364 \\
\hline Done & $40(32.8)$ & $87(37.7)$ & \\
\hline Not done & $82(67.2)$ & $144(62.3)$ & \\
\hline Unknown & 0 & 14 & \\
\hline Adjuvant systemic therapy & & & 0.303 \\
\hline Done & 99 (81.1) & $204(85.4)$ & \\
\hline Not done & $23(18.9)$ & 35 (14.6) & \\
\hline Unknown & 0 & 6 & \\
\hline Radiotherapy & & & $<0.001$ \\
\hline Yes & $122(100.0)$ & $16(7.0)$ & \\
\hline No & $0(0.0)$ & 213 (93.0) & \\
\hline Unknown & 0 & 16 & \\
\hline
\end{tabular}

Values are presented as number (\%).

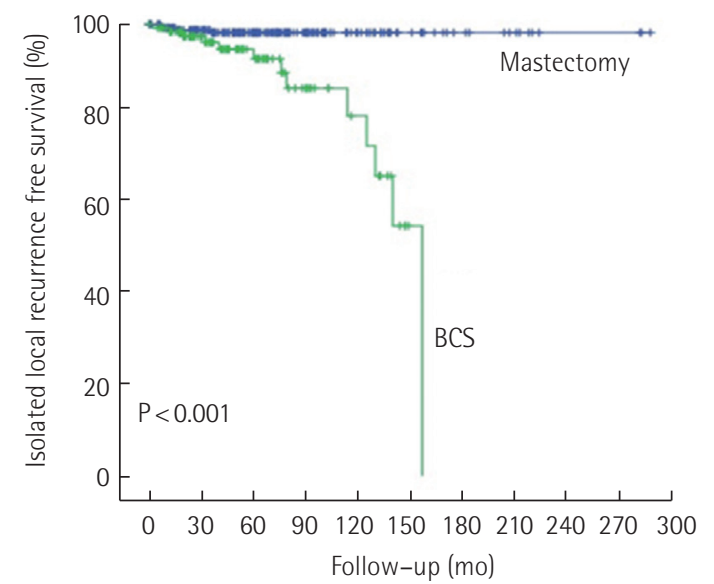

Fig. 1. (A) Isolated local recurrence-free survival and (B) overall survival curves according to local treatment in patients aged $\leq 35$ years. BCS, breast-conserving surgery. 
Table 2. Univariate analysis of isolated LR for breast cancer patients aged 35 years or less

\begin{tabular}{|c|c|c|c|c|}
\hline Characteristic & No. & 5-yr LR rate (standard error) & $10-y r$ LR rate (standard error) & P-value \\
\hline Age & & & & 0.63 \\
\hline$\leq 30 \mathrm{yr}$ & 115 & $3.0(1.7)$ & $5.5(3.0)$ & \\
\hline$>30 \mathrm{yr}$ & 246 & $3.9(1.5)$ & $8.1(3.5)$ & \\
\hline pT stage & & & & 0.176 \\
\hline 1 & 164 & $4.9(2.1)$ & $10.4(4.5)$ & \\
\hline$\|$ & 203 & $2.5(1.2)$ & $4.0(1.9)$ & \\
\hline pN stage & & & & 0.549 \\
\hline I & 249 & $3.7(1.4)$ & $8.4(3.1)$ & \\
\hline$\|$ & 118 & $3.2(1.9)$ & $3.2(1.9)$ & \\
\hline Grade & & & & 0.21 \\
\hline 1,2 & 151 & $5.7(2.1)$ & $8.0(3.1)$ & \\
\hline 3 & 76 & 0 & $7.7(7.4)$ & \\
\hline Estrogen receptor & & & & 0.585 \\
\hline Negative & 123 & $4.7(2.6)$ & $8.6(4.5)$ & \\
\hline Positive & 142 & $5.4(2.2)$ & $7.8(3.2)$ & \\
\hline Operation method & & & & $<0.001$ \\
\hline Mastectomy & 245 & $1.9(0.9)$ & $1.9(0.9)$ & \\
\hline $\mathrm{BCS}$ & 122 & 7.7 (3.2) & $20.3(7.7)$ & \\
\hline Adjuvant chemotherapy & & & & 0.05 \\
\hline Not done & 74 & $5.1(3.0)$ & $12.2(5.6)$ & \\
\hline Done & 287 & $3.1(1.2)$ & $4.3(1.7)$ & \\
\hline Adjuvant endocrine therapy & & & & 0.975 \\
\hline Not done & 226 & $3.4(1.4)$ & $8.0(3.0)$ & \\
\hline Done & 127 & $4.1(2.0)$ & $4.1(2.0)$ & \\
\hline
\end{tabular}

$L R$, local recurrence; $p T$, pathologic T stage; $p N$, pathologic $N$ stage; $B C S$, breast conservaing surgery.

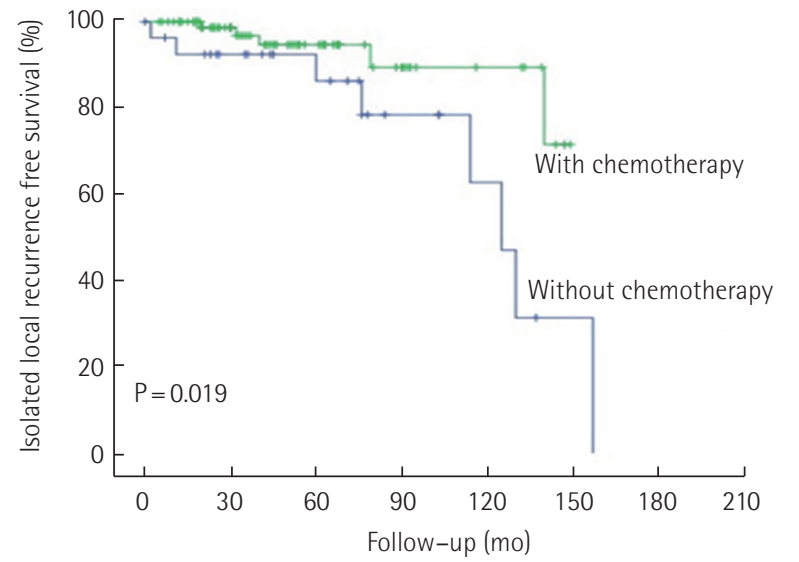

Fig. 2. Isolated local recurrence-free survival curve according to the administration of chemotherapy in patients aged $\leq 35$ years.

cording to the univariate analysis, $\mathrm{N}$ staging was the only prognostic factor that affected the overall survival rate $(\mathrm{P}<0.0001)$, while those under the age of 30 at the time of diagnosis tended to have a lower overall survival rate $(\mathrm{P}=0.082)$. In the multivariate analysis that included age at the time of diagnosis, T staging, $\mathrm{N}$ staging, surgical method, and chemotherapy as covariates, $\mathrm{N}$ staging $(\mathrm{P}$ $<0.001)$ and age at the time of diagnosis $(\mathrm{P}=0.037)$ appeared to be
Table 3. Multivariate analysis of isolated local recurrence for breast cancer patients aged 35 years or less

\begin{tabular}{lcr}
\hline Characteristic & $\begin{array}{c}\text { Relative risk } \\
\text { (confidence interval) }\end{array}$ & P-value \\
\hline Age ( $\leq 30$ yr vs. $>30 \mathrm{yr}$ ) & $0.996(0.342-2.897)$ & 0.993 \\
T stage (I vs. II) & $1.295(0.445-3.769)$ & 0.636 \\
Operation method (mastectomy vs. BCS) & $0.114(0.035-0.366)$ & $<0.001$ \\
Adjuvant chemotherapy (not done vs. done) & $2.090(0.732-5.969)$ & 0.168 \\
\hline
\end{tabular}

$\mathrm{BCS}$, breast conservaing surgery.

Table 4. Multivariate analysis of isolated local recurrence for breast cancer patients aged 35 years or less who had breast conserving treatment

\begin{tabular}{lcc}
\hline Characteristic & $\begin{array}{c}\text { Relative risk } \\
\text { (confidence interval) }\end{array}$ & P-value \\
\hline Age ( $\leq 30$ yr vs. $>30$ yr) & $1.847(0.503-6.787)$ & 0.356 \\
T stage (I vs. II) & $0.812(0.198-3.319)$ & 0.771 \\
$\begin{array}{l}\text { Adjuvant chemotherapy } \\
\text { (not done vs. done) }\end{array}$ & $4.802(1.186-19.439)$ & 0.028 \\
\hline
\end{tabular}

prognostic factors that affected the overall survival rate (Tables 4, 5). Of the patients who experienced isolated local recurrence, 3 died during the observation period; both these patients were diagnosed 
Table 5. Multivariate analysis of overall survival for breast cancer patients aged 35 years or less

\begin{tabular}{lcr}
\hline Characteristic & $\begin{array}{c}\text { Relative risk } \\
\text { (confidence interval) }\end{array}$ & P-value \\
\hline Age ( $\leq 30$ yr vs. > 30 yr) & $1.800(1.035-3.130)$ & 0.037 \\
T stage (I vs. II) & $0.700(0.387-1.266)$ & 0.238 \\
N stage (I vs. II) & $0.318(0.177-0.573)$ & $<0.001$ \\
Operation method (mastectomy vs. BCS) & $1.040(0.552-1.961)$ & 0.902 \\
Adjuvant chemotherapy (not done vs. done) & $1.532(0.737-3.183)$ & 0.253 \\
\hline
\end{tabular}

$\mathrm{BCS}$, breast conservaing surgery.

with isolated local recurrence within 2 years of surgery.

\section{DISCUSSION}

Surgery for breast cancer is gradually developing from radical surgery to advanced surgical procedures that allow for oncological safety and improve quality of life. Hence, BCS for breast cancer surgery has become more common, and sentinel lymph node biopsy is also slowly becoming the standard for axillary lymph node surgery. Although there have been conflicting reports regarding whether patients who undergo a total mastectomy have a higher quality of life than those who undergo BCS, studies conducting long-term observations have established that patients who undergo BCS tend to have a higher quality of life [16-18]. However, oncological safety is as important as quality of life. Many prospective randomized studies have verified the oncological safety of BCS. However, these studies have included a limited number of breast cancer patients under the age of 35 , making it difficult to ensure the oncological safety of BCS in patients under the age of 35 . Hence, this study attempted to verify the oncological safety of BCS in patients under the age of 35 .

To summarize the results of this study, although the isolated local recurrence rate was higher in the patients who underwent BCS than in those who underwent a total mastectomy, there were no differences in the overall survival rate, and chemotherapy lowered the isolated local recurrence rate in the patients who underwent BCS. This research only observed isolated local recurrences that were not systemic. The reason for this is that if both systemic metastasis and local recurrence occur simultaneously, the systemic metastasis typically determines the prognosis; hence, the prognosis of the local recurrence under such circumstances lacks clinical meaning.

There was a clear difference in the isolated local recurrence rate between the patients who underwent BCS and those who underwent a total mastectomy. Of the 5 patients who received BCS, 1 patient experienced recurrence in the breast that was operated upon within 10 years of surgery (under the age of 45 ) and required additional treatment. If isolated local recurrence influences the survival rate, BCS in patients under the age of 35 could be considered dangerous. However, although the patients who underwent BCS had a higher isolated local recurrence rate in this study, the overall survival rate did not differ between the 2 groups. It is possible that the number of patients and the observation period were both insufficient to verify differences in the total survival rate. However, a study that compared the 10-year survival rate in a much larger patient sample likewise reported no differences in the overall survival rate, despite differences in the local recurrence rate $[13,14]$.

Although some studies have reported that systemic metastasis increased as the isolated local recurrence rate increased, those studies failed to verify the causality between isolated local recurrence and systemic metastasis $[6,8]$. However, according to the results of the EBCTCG study, reducing local recurrence can reduce death from breast cancer in the long term. Hence, until the clinical significance of the prognosis of isolated local recurrence is clarified, this result cannot be ignored. Although there is no need to ban BCS in patients under the age of 35 simply due to the higher rate of isolated local recurrence, there is a need for sufficient consultation with the patient prior to surgery and, if the decision is made to proceed with BCS, adjuvant treatment should be provided to reduce the chance of local recurrence.

According to the findings of the present study, adjuvant chemotherapy was effective in reducing the isolated local recurrence rate. This effect has also been verified in other studies [19]. Furthermore, the general belief that local recurrence within a short period after BCS is associated with a bad prognosis was confirmed in this research, as all patients diagnosed with isolated local recurrence who died during the observation period were diagnosed within 2 years of surgery [8]. Hence, patients who are diagnosed with isolated local recurrence within 2-3 years of surgery must actively participate not only in local treatment, but in systemic treatment as well.

However, this study is limited in that it is a retrospective analysis that only analyzed patients who received long-term treatment at a single facility. Furthermore, there were differences in the tracking period between the patients who received BCS and the patients who received total mastectomy, and detailed analyses including the medication used for chemotherapy were not conducted, despite developments in breast cancer treatment that could have distorted the results due to changes in the adjuvant treatments. Furthermore, this study did not analyze certain other factors that could have affected the overall survival rate, such as characteristics of the recurrent tumors and local and systemic treatment after recurrence. Hence, follow-up research that overcomes the limitations of this 
study is required.

For breast cancer patients under the age of 35, the likelihood of isolated local recurrence after BCS is much higher than that after total mastectomy. Although there is no need to prohibit BCS just because the patient is under the age of 35 , chemotherapy based on the age at the time of diagnosis and the risk level of recurrence should be considered to reduce the possibility of isolated local recurrence. In order to produce accurate guidelines on the oncological safety of BCS in breast cancer patients under the age of 35, further research exploring the clinical significance of isolated local recurrence for the prognosis is required.

\section{CONFLICT OF INTEREST}

No potential conflict of interest relevant to this article was reported.

\section{ACKNOWLEDGEMENTS}

This research was funded by the National Health Insurance Service Ilsan Hospital.

\section{REFERENCES}

1. Veronesi U, Cascinelli N, Mariani L, Greco M, Saccozzi R, Luini A, et al. Twenty-year follow-up of a randomized study comparing breast-conserving surgery with radical mastectomy for early breast cancer. N Engl J Med 2002;347:1227-32.

2. Fisher B, Anderson S, Bryant J, Margolese RG, Deutsch M, Fisher ER, et al. Twenty-year follow-up of a randomized trial comparing total mastectomy, lumpectomy, and lumpectomy plus irradiation for the treatment of invasive breast cancer. N Engl J Med 2002; 347:1233-41.

3. van Dongen JA, Voogd AC, Fentiman IS, Legrand C, Sylvester RJ, Tong D, et al. Long-term results of a randomized trial comparing breast-conserving therapy with mastectomy: European Organization for Research and Treatment of Cancer 10801 trial. J Natl Cancer Inst 2000;92:1143-50.

4. Blichert-Toft M, Rose C, Andersen JA, Overgaard M, Axelsson CK, Andersen KW, et al. Danish randomized trial comparing breast conservation therapy with mastectomy: six years of life-table analysis. Danish Breast Cancer Cooperative Group. J Natl Cancer Inst Monogr 1992:19-25.

5. Vicini FA, Kestin L, Huang R, Martinez A. Does local recurrence affect the rate of distant metastases and survival in patients with early-stage breast carcinoma treated with breast-conserving therapy? Cancer 2003;97:910-9.

6. Touboul E, Buffat L, Belkacemi Y, Lefranc JP, Uzan S, Lhuillier P, et al. Local recurrences and distant metastases after breast-conserving surgery and radiation therapy for early breast cancer. Int J Radiat Oncol Biol Phys 1999;43:25-38.

7. Clarke M, Collins R, Darby S, Davies C, Elphinstone P, Evans V, et al. Effects of radiotherapy and of differences in the extent of surgery for early breast cancer on local recurrence and 15-year survival: an overview of the randomised trials. Lancet 2005;366:2087-106.

8. Elkhuizen PH, van de Vijver MJ, Hermans J, Zonderland HM, van de Velde CJ, Leer JW. Local recurrence after breast-conserving therapy for invasive breast cancer: high incidence in young patients and association with poor survival. Int J Radiat Oncol Biol Phys 1998;40:859-67.

9. DiBiase SJ, Komarnicky LT, Schwartz GF, Xie Y, Mansfield CM. The number of positive margins influences the outcome of women treated with breast preservation for early stage breast carcinoma. Cancer 1998;82:2212-20.

10. Park CC, Mitsumori M, Nixon A, Recht A, Connolly J, Gelman R, et al. Outcome at 8 years after breast-conserving surgery and radiation therapy for invasive breast cancer: influence of margin status and systemic therapy on local recurrence. J Clin Oncol 2000;18: 1668-75.

11. Voogd AC, Nielsen M, Peterse JL, Blichert-Toft M, Bartelink H, Overgaard $\mathrm{M}$, et al. Differences in risk factors for local and distant recurrence after breast-conserving therapy or mastectomy for stage I and II breast cancer: pooled results of two large European randomized trials. J Clin Oncol 2001;19:1688-97.

12. Mirza NQ, Vlastos G, Meric F, Buchholz TA, Esnaola N, Singletary SE, et al. Predictors of locoregional recurrence among patients with early-stage breast cancer treated with breast-conserving therapy. Ann Surg Oncol 2002;9:256-65.

13. Kroman N, Holtveg H, Wohlfahrt J, Jensen MB, Mouridsen HT, Blichert-Toft M, et al. Effect of breast-conserving therapy versus radical mastectomy on prognosis for young women with breast carcinoma. Cancer 2004;100:688-93.

14. Coulombe G, Tyldesley S, Speers C, Paltiel C, Aquino-Parsons C, Bernstein $\mathrm{V}$, et al. Is mastectomy superior to breast-conserving treatment for young women? Int J Radiat Oncol Biol Phys 2007;67:1282-90.

15. Han W, Kang SY. Relationship between age at diagnosis and outcome of premenopausal breast cancer: age less than 35 years is a reasonable cut-off for defining young age-onset breast cancer. Breast Cancer Res Treat 2010;119:193-200.

16. Ohsumi S, Shimozuma K, Kuroi K, Ono M, Imai H. Quality of life of breast cancer patients and types of surgery for breast cancer: current status and unresolved issues. Breast Cancer 2007;14:66-73.

17. Arndt V, Stegmaier C, Ziegler H, Brenner H. Quality of life over 5 years in women with breast cancer after breast-conserving therapy 
versus mastectomy: a population-based study. J Cancer Res Clin Oncol 2008;134:1311-8.

18. Engel J, Kerr J, Schlesinger-Raab A, Sauer H, Holzel D. Quality of life following breast-conserving therapy or mastectomy: results of a 5-year prospective study. Breast J 2004;10:223-31.

19. van der Sangen MJ, van de Wiel FM, Poortmans PM, Tjan-Hei- jnen VC, Nieuwenhuijzen GA, Roumen RM, et al. Are breast conservation and mastectomy equally effective in the treatment of young women with early breast cancer? Long-term results of a population-based cohort of 1,451 patients aged $\leq 40$ years. Breast Cancer Res Treat 2011;127:207-15. 